\title{
Modeling the pressure characteristics of parallel chokes used in managed pressure drilling and related experiments
}

\author{
Liu Gonghui ${ }^{1,2}$, Zhang Tao ${ }^{1 *}$, Li Jun ${ }^{1}$ and Yang Yulong ${ }^{1}$ \\ ${ }^{1}$ China University of Petroleum, Beijing 102249, China \\ ${ }^{2}$ Beijing Information Science \& Technology University, Beijing 100101, China \\ (C) China University of Petroleum (Beijing) and Springer-Verlag Berlin Heidelberg 2012
}

\begin{abstract}
Based on the local resistance computation model for a choke valve and using the flow characteristics of choke valves, we studied the relationships between the back pressure of a parallel choke assembly and the opening extent of choke valves and developed a model to characterize the pressure regime of the manifold assembly. A comparison of pressure characteristic curves shows that a parallel choke manifold assembly has obvious advantages over the conventional serial type including high linearity of pressure-regulating characteristics curves, the elimination of the overshoot interval, wider effective regulating interval and the higher system security. Laboratory hydraulic experiments have validated the capability of a back pressure control model for the parallel choke assembly to accurately control pressure. This study is of great theoretical and practical significance to further improve the performance of chokes used in managed pressure well drilling.
\end{abstract}

Key words: MPD, choke, parallel choke, pressure control

\section{Introduction}

Managed pressure drilling (MPD) is one of the most advanced drilling techniques currently available for the oil industry and automatic chokes are an important component of the MPD technology. Chokes can be used to provide and control wellhead back pressure and further offer an indirect control of the bottomhole pressure (Miller et al, 2006; Finley et al, 2006; Santos et al, 2004; 2005; 2007a; 2007b; 2008; Godhavn, 2009; Chustz et al, 2007; 2008; Fredericks et al, 2008; Calderoni et al, 2009). A traditional manifold assembly typically has only one choke valve and the magnitude of the wellhead back pressure is determined by how far the choke valve is opened. There exists an overshoot interval, an invalid interval and a valid interval when the choke valve is opened due to the high non-linearity between pressure drop and the extent of the opening of the choke valve (Zhang, 2007). When the choke valve is working in the overshoot interval, pressure is highly sensitive to changes in the extent of the opening of the valve making pressure control very difficult. When the choke valve is working in the invalid interval, the pressure changes only slightly with changes in the extent of the opening of the valve and pressure control is slow. Specially engineered choke valves can widen the optimum pressure interval but are unable to eliminate the overshoot interval. Besides, such choke valves are expensive and will

*Corresponding author. email: chonpdy@163.com

Received January 16, 2012 thus raise the cost of operation. As the underground drilling environment is increasingly complex and harsh and the safe drilling pressure window becomes narrower, well drilling has increasingly strict requirements for wellhead back pressure control and the treatment of high pressure differentials is no longer the primary object of surface throttling. Rather the priority is given to increasing the accuracy of control of wellhead back pressure (down to within $0.3 \mathrm{MPa}$ ) (Chen et al, 1998; Zhou et al, 2011). On the other hand, limited by operating conditions, current studies of choke valves are primarily focused on flow characteristics when pressure differentials are constant (Lyons 1991). By studying the local resistance of choke valves and making use of the functional relationship between relative flow and valve opening, we established a choke valve pressure characteristics model (reflecting the relationship between pressure differential and valve opening) and, based on the model, developed a model to characterize the pressure regime of a choke assembly with two piping lines connected to each other in parallel. This model can be used to aid in the design and selection of specialized choke valves used in managed pressure drilling. Modeling shows that a parallel choke assembly has many advantages over serial ones including high control accuracy, safer operation and fast regulation.

\section{Pressure regulation characteristics of conventional chokes}

Before studying the characteristics of the pressure regime 
of a parallel choke assembly, we need to look at those of a choke valve. To date, the flow characteristics of fluids in a choke valve have been well studied when the pressure differential is constant. Based on the relationship between relative flow rate and valve opening, the flow characteristics of fluids in the choke valve are categorized into linear characteristics, equal percentage characteristics, parabolic characteristics and quick opening characteristics. However, no definite modeling has been proposed so far to characterize the relationship between the pressure differential and extent of opening of choke valves at a constant flow rate. As mud pumps are typically set at constant displacements in a drilling operation, it is very important to manage pressure drilling to model the relationship between the pressure differential and extent of opening of choke valves when the flow rate is constant.

A conventional choke has a choke valve (shown in Fig. 1(a) as piping equipped with one choke valve). We set two points - "a" and "b" - on the piping upstream and downstream of the choke valve for analysis.

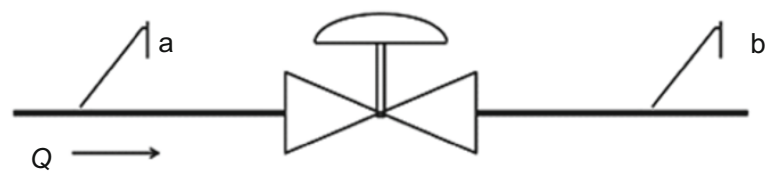

(a) Pipeline with a single choke

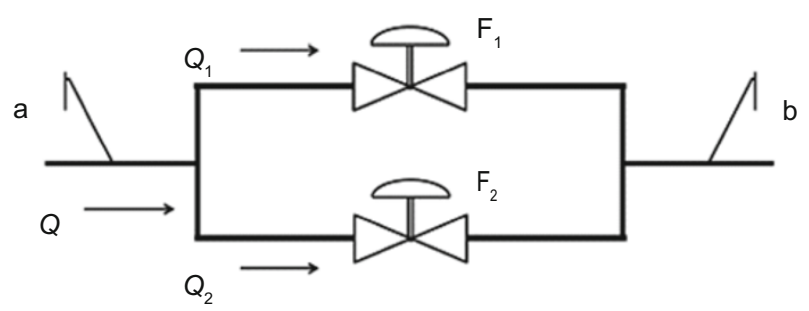

(b) Pipeline with two chokes in paralle

Fig. 1 A comparison between a conventional choke (a) and parallel chokes (b)

The results of analysis of the fluid flow characteristics in the choke valve can be used to define the pressure characteristics. As the pressure difference between the two ends of the valve must be constant when the flow characteristic function is used and the pressure characteristic function can only be used when the flow rate is constant, an intermediate variable independent of flow and pressure must be introduced. Three states were set for theoretical analysis. From state 1 to state 2, the pressure differential is constant, while from state 1 to state 3 , the flow rate is constant.

State 1: When the choke valve is fully opened $(100 \%)$, the fluid passing through the valve is in an equilibrium state (Yuan, 1986).

$$
\Delta P_{100}=\frac{\rho}{2} \frac{\xi_{100}}{A^{2}} Q_{100}^{2}
$$

where $\Delta P_{100}$ is the pressure differential between the piping upstream and downstream of the valve when the valve is fully opened, $\mathrm{Pa} ; Q_{100}$ is the rate of flow passing through the fully opened choke valve, $\mathrm{m}^{3} / \mathrm{s} ; \xi_{100}$ is the valve resistance coefficient when the choke valve is fully opened, dimensionless; $A$ is the inner cross-sectional area of the piping downstream of the choke valve, $\mathrm{m}^{2} ; \rho$ is the density of the fluid, $\mathrm{kg} / \mathrm{m}^{3}$.

State 2: If the pressure differential in state 1 is maintained $\left(\Delta P_{2}=\Delta P_{100}\right)$, changing the opening extent of the choke valve will make the system reach a new equilibrium state.

$$
\Delta P_{2}=\frac{\rho}{2} \frac{\xi_{2}}{A^{2}} Q_{2}^{2}
$$

where $\Delta P_{2}$ is the pressure differential between the piping upstream and downstream of the valve at the state $2, \mathrm{~Pa}$; $Q_{2}$ is the rate of flow passing through the choke valve in state $2, \mathrm{~m}^{3} / \mathrm{s} ; \xi_{2}$ is the valve resistance coefficient in state 2 , dimensionless.

The combination of Eqs. (1) and (2) gives:

$$
\frac{Q_{2}}{Q_{100}}=\sqrt{\frac{\xi_{100}}{\xi_{2}}}
$$

As the resistance coefficient of the choke valve, $\xi$ is related to the shape and extent of opening of the valve disk as well as the nature of the fluid and is unrelated to pressure differential and flow rate, at a given extent of opening of the valve, the $\xi_{100} / \xi_{2}$ is a fixed value.

The relative flow of the choke valve can be expressed by the formula of flow characteristic as follows:

$$
\frac{Q_{2}}{Q_{100}}=f(K)
$$

where $f(\cdot)$ is the flow characteristic function of the choke valve and $K$ is the opening extent of the choke valve. Eq. (4) is valid on condition that the pressure differentials at the two ends of the choke valve are equal. The expression of $f(\cdot)$ are different under various flow characteristics of the choke valve.

According to Eqs. (3) and (4), we obtained:

$$
f(K)=\sqrt{\frac{\xi_{100}}{\xi_{2}}}
$$

The functional relationship between the resistance coefficient and extent of opening of the choke valve is established in Eq. (5), which is independent of the pressure differential and flow rate.

State 3: If the extent of opening of the choke valve in state 2 is maintained, $\xi_{3}=\xi_{2}$. If the flow rate of the fluid passing through the choke valve is adjusted to make $Q_{3}=Q_{100}$, the system will reach a new equilibrium state.

$$
\Delta P_{3}=\frac{\rho}{2} \frac{\xi_{3}}{A^{2}} Q_{3}^{2}
$$

where $\Delta P_{3}$ is the pressure differential between the piping upstream and downstream of the valve in state $3, \mathrm{~Pa} ; Q_{3}$ is the rate of flow passing through the choke valve in state $3, \mathrm{~m}^{3} / \mathrm{s}$; 
$\xi_{3}$ is the valve resistance coefficient in state 3 , dimensionless.

The combination of Eqs. (1), (3-5) and (6) gives:

$$
\frac{\Delta P_{3}}{\Delta P_{100}}=\frac{\xi_{3}}{\xi_{100}}=\frac{1}{f^{2}(K)}
$$

Eq. (7) is only the pressure characteristic model of the choke valve, in which the relationship between the pressure differential and extent of opening of the choke valve is determined. The application condition of this model is that the fluid in the piping is incompressible, the flow rate is constant and the flow is in a turbulent state. The fluid flow in managed pressure drilling meets all the conditions.

If the opening of the choke valve widens gradually from 0 to $100 \%$, we can obtain a series of pressure curves of the choke valve, as shown in Fig. 2.

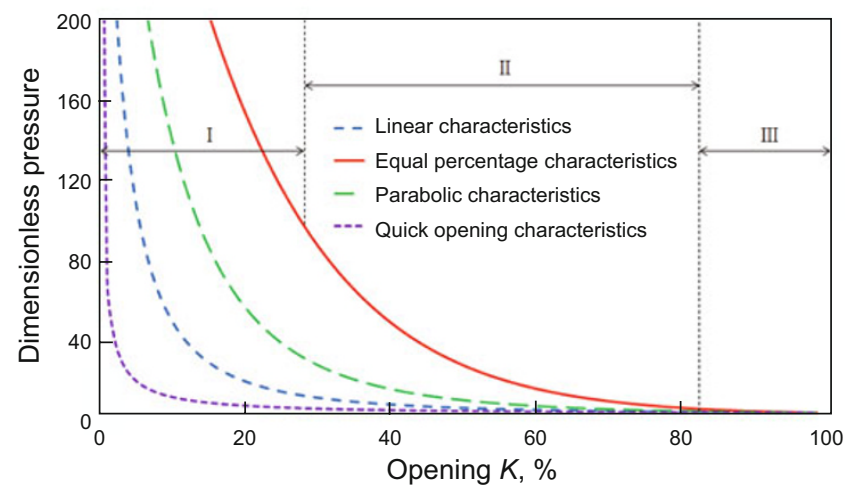

Fig. 2 Pressure characteristic curves of the choke valve

As shown in Fig. 2, we can see that the relationship between the pressure differential and the opening extent of the choke valve is nonlinear. The degree of the non-linearity is related to the flow characteristics while the fluid is passing through the choke valve. We use a choke valve with equal percentage characteristics and good linearity for analysis and divide the opening of the choke valve into three intervals based on the pressure curves of the valve - the overshoot interval, the valid interval and the invalid interval. When the choke valve is working in the overshoot interval, the pressure differential of the choke valve is highly sensitive to changes in the extent of opening of the valve and slight changes in the valve opening can result in a dramatic change in pressure making pressure control very difficult. When the choke valve is working in the invalid interval, a change in valve opening has little effect on pressure, thus resulting in a delay in pressure control. In the valid interval, there is a relatively good linearity between the extent of opening of the choke valve and the pressure differential so the pressure can be regulated by adjusting the extent of opening of the valve. Due to structural limitations, all choke valves have these three intervals. Only the shares of the intervals vary from one type of choke valve to another, determined by the shape of valve disk. The choke valves used in conventional chokes use specially engineered disks to increase the valid interval but are unable to eliminate the overshoot range. As the back pressure of the choke valve can affect bottom hole pressure and riser pressure when the extent of opening of the choke valve is too small, there will be a risk of fracturing the formation or forcing operators to turn on the safety valve of mud pumps, thereby impacting operations.

\section{Hydraulic characteristics of the parallel choke}

A parallel choke consists of two or more parallel branch lines each of which has a choke valve. Take a choke assembly with two branch lines for example (Fig. 1(b)). The parallel choke consists of a primary regulating line and a secondary regulating line. The diameters of the piping used as the branch lines are the same. In Fig. 1(b), the choke valve installed on the primary regulating line is $F_{1}$ and that on the secondary regulating line is $\mathrm{F}_{2}$.

Parallel piping has two characteristics (Yuan, 1986; Yang and Zhang, 2001):

1) The resistance to flow of each branch line of the piping are equal: $h_{f 1}=h_{f 2}$

2) The total flow rate of parallel piping is the sum of the flow rates of all branch lines:

\section{$Q=Q_{1}+Q_{2}$}

If the local resistance other than that at the choke valve in the parallel choke are neglected, the local resistance losses of the branch lines are:

$$
h_{f 1}=\xi_{1} \frac{Q_{1}^{2}}{2 g A^{2}}
$$

$$
h_{f 2}=\xi_{2} \frac{Q_{2}^{2}}{2 g A^{2}}=\xi_{2} \frac{\left(Q-Q_{1}\right)^{2}}{2 g A^{2}}
$$

where $h_{f 1}$ and $h_{f 2}$ are the local resistances to flow at choke valves $\mathrm{F}_{1}$ and $\mathrm{F}_{2} ; \xi_{1}$ and $\xi_{2}$ are the resistance coefficients of choke valves $\mathrm{F}_{1}$ and $\mathrm{F}_{2} ; Q_{1}$ and $Q_{2}$ are the flow rates passing through choke valves $\mathrm{F}_{1}$ and $\mathrm{F}_{2}$ and $Q$ are the sum of the flow rate of the fluid passing through choke valves $F_{1}$ and $F_{2}$.

Since $h_{f 1}=h_{f 2}$, we have:

$$
Q_{1}=\frac{Q}{1+\sqrt{\frac{\xi_{1}}{\xi_{2}}}}=\frac{Q}{1+\sqrt{\frac{\xi_{1} / \xi_{1-100}}{\xi_{2} / \xi_{1-100}}}}
$$

If the two choke valves are identical, then $\xi_{1-100}=\xi_{2-100}$, and Eq. (10) can be rewritten as:

$$
Q_{1}=\frac{Q}{1+\sqrt{\frac{\xi_{1} / \xi_{1-100}}{\xi_{2} / \xi_{2-100}}}}=\frac{Q}{1+\frac{f\left(K_{2}\right)}{f\left(K_{1}\right)}}
$$

where, $\xi_{1-100}$ and $\xi_{2-100}$ are the valve resistance coefficients when the choke valves $\mathrm{F}_{1}$ and $\mathrm{F}_{2}$ are fully opened; $K_{1}$ and $K_{2}$ are the opening extents of the choke valves $\mathrm{F}_{1}$ and $\mathrm{F}_{2}$.

Eq. (11) is a model depicting the flow distribution in the piping of a choke with two branch lines connected in parallel when the flow rate is constant. The following equation can 
be obtained when using Eq. (11) to calculate dimensionless pressure:

$$
\frac{\Delta P_{1}}{\Delta P_{1-100}}=\frac{\frac{\rho}{2} \frac{\xi_{1}}{A^{2}} Q_{1}^{2}}{\frac{\rho}{2} \frac{\xi_{1-100}}{A^{2}} Q_{1-100}^{2}}=\frac{\xi_{1}}{\xi_{1-100}}\left(\frac{Q_{1}}{Q_{1-100}}\right)^{2}
$$

where $Q_{1-100}$ is the rate of flow passing through the main choke valve $F_{1}$ when the opening of $F_{1}$ is $100 \%$ and that of $F_{2}$ is 0 , i.e., $Q_{1-100}=Q$. Then, Eq. (12) can be further expressed as follows:

$$
\frac{\Delta P_{1}}{\Delta P_{1-100}}=\frac{\xi_{1}}{\xi_{1-100}}\left(\frac{Q_{1}}{Q}\right)^{2}=\left[\frac{1}{f\left(K_{1}\right)+f\left(K_{2}\right)}\right]^{2}
$$

If the local resistances other than that at the choke valve in the parallel choke are neglected, the pressure differential of the main choke valve $F_{1}$ is equal to that of the secondary choke valve $F_{2}$ and also to that of the choke unit as a whole. Eq. (13) is a pressure characteristic model for a parallel choke when the total flow rate is constant. From this model, we can see that the pressure differential between the two ends of the choke valve of the parallel choke is related to the extents of opening of both choke valves. When the opening extent of $F_{2}$ is 0 , Eq. (13) is the same as Eq. (7), and when the opening extent of $F_{1}$ is 0 , Eq. (13) changes to:

$$
\frac{\Delta P_{1}}{\Delta P_{1-100}}=\left[\frac{1}{f\left(K_{2}\right)}\right]^{2}
$$

From Eq. (14), we can see that even if the choke valve $F_{1}$ is completely shut off, the pressure differential between its two ends can still be controlled by regulating the opening of the choke valve $F_{2}$ and this is also what we see in the choke system in reality.

Take equal percentage throttles for an example. When the opening of the choke installed in the secondary branch is $0,30 \%, 50 \%$ and $70 \%$ separately, the main choke opening gradually increases from 0 to $100 \%$ and we can obtain the pressure characteristic curves of the parallel choke according to Eq. (13). (Fig. 3)

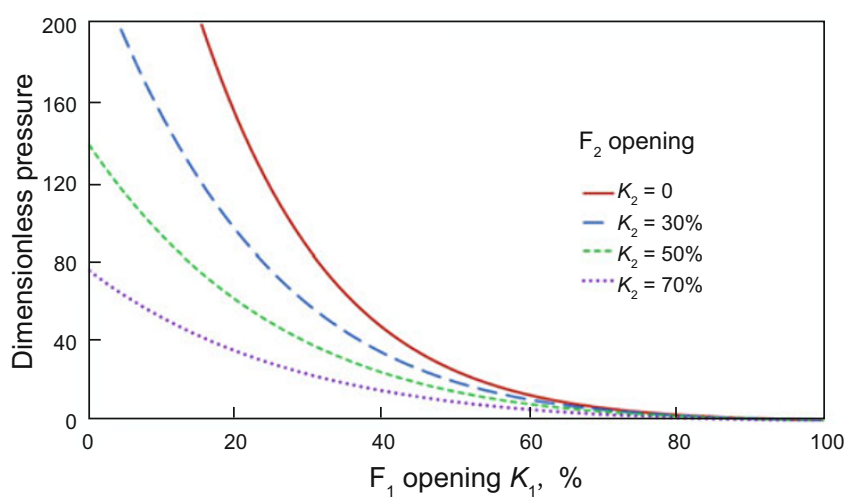

Fig. 3 Pressure characteristic curves of the parallel choke
Fig. 3 shows the pressure characteristic curves of the parallel choke when the opening of the choke in the branch line is fixed. By comparing the four curves in Fig. 3, we know that the linearity of the pressure characteristic curves of the parallel choke is optimized with an increase in the auxiliary choke opening.

As the opening of choke valve $F_{2}$ increases, the controllable pressure range of the choke decreases, so the role of the auxiliary choke is to adjust the range of the choke control on back pressure.

According the curves shown in Fig. 3, this paper proposes a simple control scheme for parallel chokes. Manually setting a maximum control back pressure, when the drilling fluid density and displacement are constant, the maximum control back pressure corresponds strictly to the opening of the auxiliary choke. Simultaneously, the main choke is controlled by an traditional control algorithm. If the back pressure control range is fixed, the auxiliary choke opening is constant. Thus the inlet pressure of the choke will still be within the safe range when the main choke opening is 0 . The main choke can work in the opening of $0-100 \%$ so the overshoot range is eliminated by the parallel choke completely and then the effective range enlarged and the security of the choke improved.

Above is the simple control scheme for parallel chokes, i.e., when the auxiliary choke keeps a constant opening, the back pressure can be controlled within a given range by varying the opening of the main choke (0-100\%). In addition, there is a more advanced control scheme.

The main and auxiliary chokes are the same. When the openings of both chokes gradually increase from 0 to $100 \%$, the pressure characteristic curves of the parallel choke will turn into a curved surface (Fig. 4)

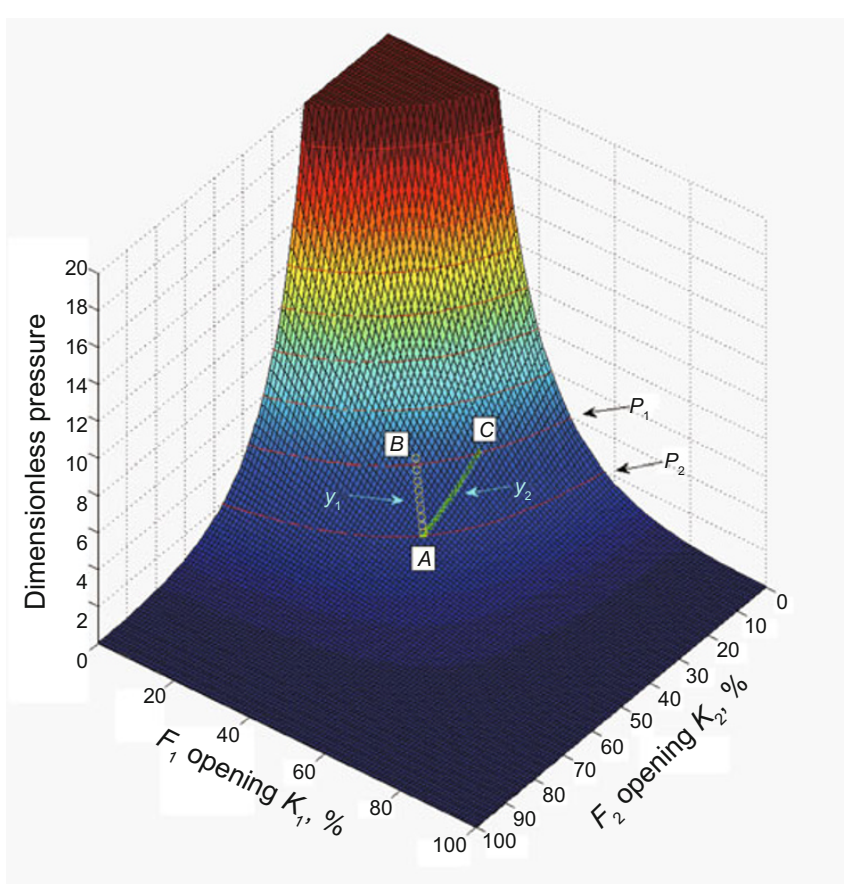

Fig. 4 Curved surface of pressure characteristic of the parallel choke 
Because the main choke $F_{1}$ and the auxiliary choke $F_{2}$ are of the same type and have the same pressure characteristics, the curved surface, which indicates the pressure characteristic of the parallel choke, is bilaterally symmetrical. For the safety in drilling operations, the back pressure must be controlled within a certain range, so there is a maximum pressure surface in Fig. 4.

The advantage of parallel chokes is that the pressure can be regulated along any curve on the curved surface. The surface function can be expressed as as $\partial f\left(K_{1}, K_{2}\right)$. In order to ensure the stability of the control system, we set a condition on the control scheme in which the pressure regulation curves should follow the rules of isotropy and unipolarity, which means that when the pressure is adjusted from one point to another, the variation trend of the opening of each choke will remain unchanged and the trends of the opening of both chokes are the same. It can be expressed as follows:

$$
\frac{\partial f\left(K_{1}, K_{2}\right)}{\partial K_{1}} \frac{\partial f\left(K_{1}, K_{2}\right)}{\partial K_{2}} \geq 0
$$

In Fig. 4, as $\mathrm{F}_{2}$ is an auxiliary choke, the smaller its opening is, the higher the controlled pressure of the parallel choke will be, but the control accuracy will decrease. The limit case is that at $K_{2}=0$, the characteristic pressure curve is the same as that of one choke.

The more advanced control scheme is as follows: $F_{1}$ and $\mathrm{F}_{2}$ work simultaneously, so that the back pressure changes along the direction of the isobar gradient and the regulation will be speeded up.

In Fig. 4, $P_{1}$ and $P_{2}$ are the isobars when the pressures are respectively $P_{1}$ and $P_{2}$; point $A$ is on the isobar $P_{2}$ while $B$ and $C$ are on the isobar $P_{1}$. The coordinates of these three points are $A\left(K_{1 \mathrm{~A}}, K_{2 \mathrm{~A}}\right), B\left(K_{1 \mathrm{~B}}, K_{2 \mathrm{~B}}\right)$ and $C\left(K_{1 \mathrm{C}}, K_{2 \mathrm{C}}\right)$. These coordinate values indicate the opening of chokes $\mathrm{F}_{1}$ and $\mathrm{F}_{2}$ in the parallel choke. The pressure curve in the simple control scheme is shown as $y_{2}$, where the specific path of $y_{2}$ is as follows: Keeping the opening of $\mathrm{F}_{2}$ constant and adjusting that of $F_{1}$ from $K_{1 \mathrm{~A}}$ to $K_{1 \mathrm{C}}$. The pressure curve in the advanced control scheme is shown as $y_{1}$, where curve $y_{1}$ starts from point $A$, reaches point $B$ along the direction of the isobar gradient at $A$ and the specific path is as follows: Adjust the extent of opening of $F_{1}$ from $K_{1 \mathrm{~A}}$ to $K_{1 \mathrm{~B}}$ and simultaneously adjust extent of opening of $F_{2}$ from $K_{2 \mathrm{~A}}$ to $K_{2 \mathrm{~B}}$. Meanwhile, $y_{1}$ will move along the gradient direction of isobar $P_{2}$, so $\left|K_{1 A}-K_{1 B}\right|<\left|K_{1 A}-K_{1 C}\right|$. Because the actuators of $\mathrm{F}_{1}$ and $\mathrm{F}_{2}$ can move simultaneously and $\mathrm{F}_{1}$ and $\mathrm{F}_{2}$ can reach $P_{1}$ from $P_{2}$ fast following path $y_{1}$, the parallel choke has a higher pressure regulation speed in the advanced control scheme.

Currently, a choke is composed of a work branch and a standby branch in parallel, so there is no need to modify the hardware, and the parallel choke technology can be realized only by amending the control software according to the parallel choke control scheme. Although parallel chokes place higher requirements on the control algorithm compared to traditional chokes, due to the rapid development of computer technology and control theories, it is no longer a problem to control the multiple-input and single-output (MISO) system and the control speed of computer is much faster than that of the throttles. Essentially, parallel chokes reduce the quality requirement on chokes by improving the control system performance.

\section{Hydraulic tests of parallel chokes}

To verify the theoretical analysis results and test the pressure regulation capability of parallel chokes, hydraulic experiments have been conducted on parallel chokes. A schematic diagram of the experimental system is shown in Fig. 5

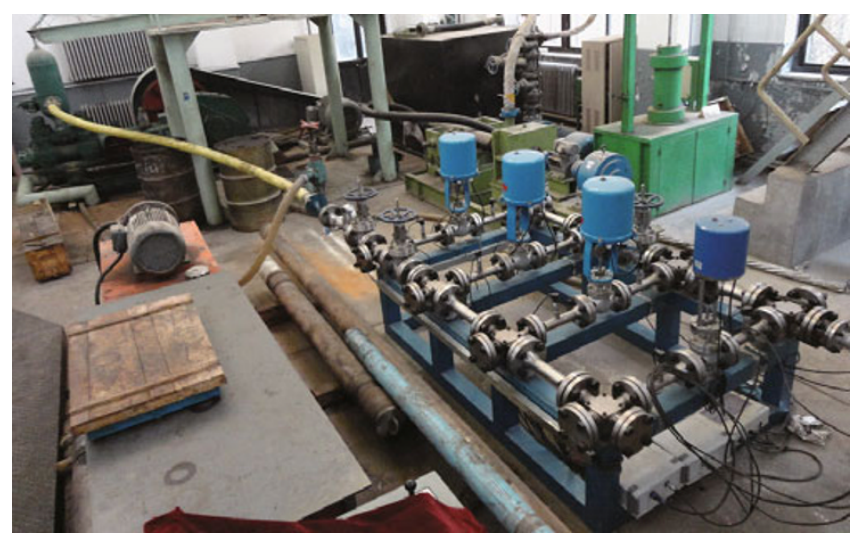

Fig. 5 The parallel choke for measuring pressure characteristics

To ensure the rate of fluid flow passing through the choke is constant, a piston pump with a nominal displacement of 15 $\mathrm{L} / \mathrm{s}$ was used in the experimental system. The parallel choke actually used in the experiment had four branches and each branch contained a choke. In the experiments, we closed two of the branches and kept the other two working. The two chokes were numbered as $F_{1}$ and $F_{2}$, and their structures were the same as the data used in the theoretical analysis. The experiments were performed in both manual control mode and automatic control mod.

In the manual control mode, the opening of the chokes $F_{1}$ and $F_{2}$ were controlled manually and the experimental procedure is as follows:

Step 1: Set the opening of the choke $F_{2}$ to 0 and then regulate the opening of $\mathrm{F}_{1}$. The opening of $\mathrm{F}_{1}$ is gradually decreased from $100 \%$, with a change of $1 \%$ each time. Record the opening of $\mathrm{F}_{1}$ and the corresponding back pressure value. For security, the highest pressure value is set to 1.5 $\mathrm{MPa}$. When the back pressure value reaches $1.4 \mathrm{MPa}$, stop regulating the opening of $\mathrm{F}_{1}$, which will be $78 \%$ at this point.

Step 2: Set the opening of the choke $\mathrm{F}_{2}$ to $78 \%$ and then regulate the opening of $F_{1}$. The opening of $F_{1}$ is gradually decreased from $100 \%$, changed by $1 \%$ each time. Record the opening of $\mathrm{F}_{1}$ and the corresponding back pressure value. When the opening value decreases to 0 , the back pressure value reaches $1.4 \mathrm{MPa}$.

Step 3: Increase the opening of $\mathrm{F}_{2}$ to $86 \%$ and regulate the opening of $F_{1}$. The opening of $F_{1}$ is gradually decreased from $100 \%$, changed by $1 \%$ each time. Record the opening of $F_{1}$ and the corresponding back pressure value.

Step 4: Increase the opening of $\mathrm{F}_{2}$ to $90 \%$ and regulate the 
opening of $F_{1}$. The opening of $F_{1}$ is gradually decreased from $100 \%$, changed by $1 \%$ each time. Record the opening of $F_{1}$ and the corresponding back pressure value.

The results obtained are shown in Fig. 6

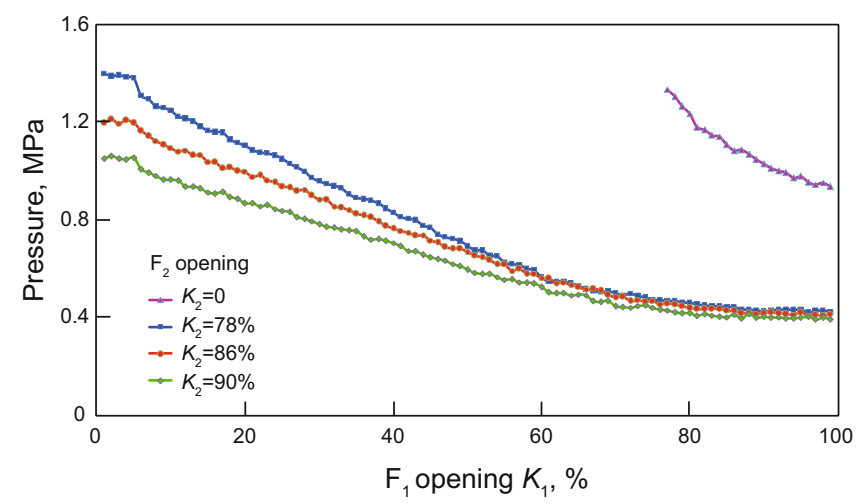

Fig. 6 A comparison of pressure characteristic curves of the parallel choke

Fig. 6 shows that when the opening of the auxiliary choke $F_{2}$ was 0 , the back pressure increased quickly (the local resistance before the choke $F_{1}$ was very large when a single choke was used so the initial pressure was relatively high in single-choke experiments). However, when the opening of the auxiliary choke was not 0 , the back pressure increased slowly and steadily as the opening of the main choke $F_{1}$ descended. The pressure regulation curves of the main choke $F_{1}$ changed as the opening of the auxiliary choke $\mathrm{F}_{2}$ varied.

A comparison between Figs. 6 and 3 shows that the experimental results and theoretical analysis of parallel chokes basically have the same variation which proves the feasibility of the theoretical analysis. Due to the use of dimensionless pressure in Fig. 3 which can only be a basis for qualitative analysis, we cannot carry out an error analysis between the curves in the two figures.

In the automatic control mode, the pressure value (PV) was set to $0-100 \%$ and the corresponding pressure was $0-1$ MPa. The tests included a simple automatic control mode test and an advanced automatic control mode test. In the simple automatic control mode, the opening of the main choke $F_{1}$ was controlled by control procedures, while the choke $\mathrm{F}_{2}$ and the back pressure value were controlled manually. In the advanced automatic control mode, the openings of the chokes $F_{1}$ and $F_{2}$ both were controlled by control procedures while the back pressure value was controlled manually. The experimental procedure in the simple automatic control mode are as follows:

Step 1: When the auxiliary choke opening is 0 , modify the set value (SV) from the initialization to $45 \%$, and observe the system control effect. Once the system is stable (absolute error is less than $0.02 \mathrm{MPa}$ ), modify the set value from $45 \%$ to $30 \%$ and observe the system control effect.

Step 2: Adjust the auxiliary choke opening to $20 \%, 40 \%$ and $60 \%$ separately and repeat Step 1.

The test results are shown in Fig. 7.

The experimental results obtained when the manifold was in the simple control mode, show that with the parallel choke

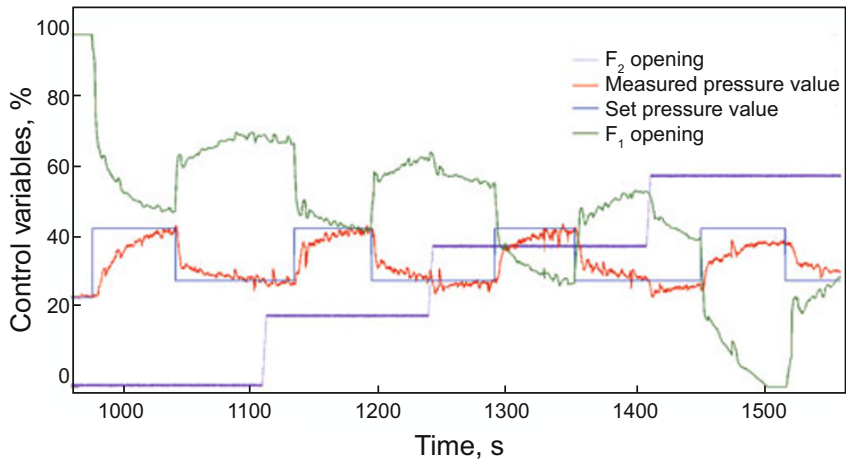

Fig. 7 The simple automatic control mode test of the parallel choke

system precise control of pressure was achieved. When the $F_{2}$ opening changed, the corresponding $F_{1}$ opening would be different even at the same pressure value. So the $F_{1}$ opening can work in the optimal interval of the choke by controlling $\mathrm{F}_{2}$ opening .

In the advanced automatic control mode, the set valve was modified and the system control effect under different control modes was observed. The results are shown in Fig. 8.

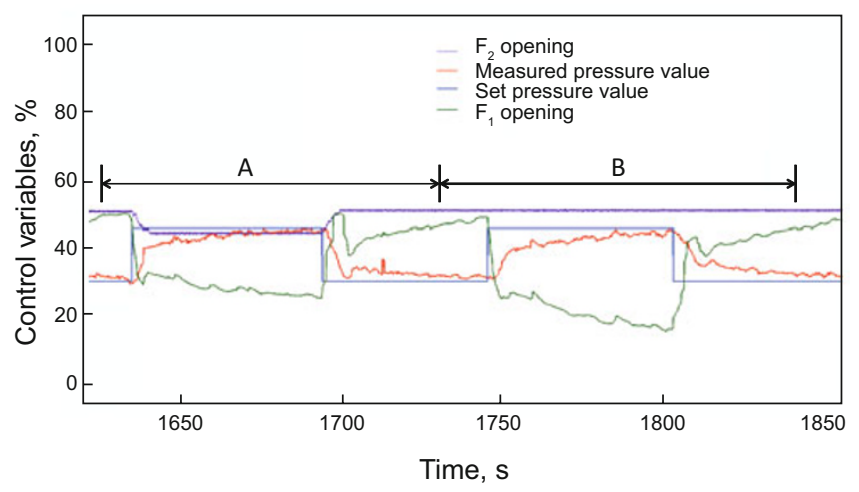

Fig. 8 The advanced automatic control mode test of the parallel choke A: Advanced automatic control mode; B: Simple automatic control mode

By comparing the test curves of part A and part B in Fig. 8, obviously, we can conclude that the pressure control speed of the system in the advanced automatic control mode was faster than that in the simple automatic control mode. Besides, according to the system configuration, when the error exceeded a certain value, $\mathrm{F}_{2}$ performs automatic control; when the error is small, the $F_{2}$ opening remained the same, while $F_{1}$ finely regulated the pressure. Therefore, the parallel choke regulation is faster and more accurate in the advanced automatic control mode.

In summary, experimental results show that the overshoot range can be eliminated completely by using the parallel choke, and the main choke can work in the range $0-100 \%$; by regulating the opening of $\mathrm{F}_{2}$, the main choke can work in the optimal range; by the cofactor of $\mathrm{F}_{2}$, system control speed can be improved.

Since the chokes used in the experimental system were the most common ones on the market, the response speed and control accuracy cannot be mentioned in the same breath as 
advanced chokes used in the field but still it can be proved that parallel chokes have higher advantages on back pressure control. Obviously, we may obtain better control effect by using more advanced chokes.

\section{Conclusions}

1) Based on the flow characteristic function of a choke valve when the pressure differential is constant, we developed a model characterizing the pressure regime of choke valves when the flow rate is constant and a model characterizing the pressure regime of a choke with two branch lines connected in parallel. The models were validated through experiments. The pressure characteristic model of the parallel choke can be used to aid in selecting choke valves in managed pressure drilling.

2) A model was established for characterizing the pressure of the parallel chokes based on a theoretical derivation and was validated by experimental results. When working under the same conditions and with the same choke valves, the parallel choke can eliminate the overshoot interval of choke valves and extend the valid interval. It has improved linearity and higher regulation precision compared to the traditional choke.

3) The paper proposes two control schemes for chokes connected in parallel and points out that the control of the parallel choke can be achieved by only modifying the control software for the existing chokes.

4) In the parallel choke system, the choke valve on the secondary branch line is used to regulate the controllable back pressure range, and to enable the main choke valve to always work in the optimum opening interval for different back pressure regimes to optimize control precision and thereby lower the requirements for choke valve manufacturing technology itself.

\section{Acknowledgements}

This research is supported by Important National Science \& Technology Specific Projects (2008ZX05021-003) and National Natural Science Funds (50974021).

\section{References}

Calderoni A, Girola G, Maestrami M, et al. Micro flux control and ECD continuous-circulation valves allow operator to reach HP/HT reservoirs for the first Time. IADC/SPE Managed Pressure Drilling and Underbalanced Operations Conference \& Exhibition, 12-13 February 2009, San Antonio, Texas (SPE 122270)

Chen H L. Problems and improvement of chokes. Gas Industry. 1998. (4): 104-105 (in Chinese)

Chustz M J, May J, Wallace C, et al. Managed pressure drilling with dynamic annular pressure-control system proves successful in redevelopment program on auger TLP in deepwater Gulf of Mexico. IADC/SPE Managed Pressure Drilling \& Underbalanced Operations, 28-29 March 2007, Galveston, Texas, U.S.A. (SPE 108348)

Chustz M J, Smith L D, and Dell D. Managed pressure drilling success continues on auger TLP. IADC/SPE Drilling Conference, 4-6 March 2008, Orlando, Florida, USA (SPE 112662)

Finley D, Shayegi S, Ansah J, et al. Reservoir knowledge and drillingbenefits comparison for underbalanced and managed pressure drilling operations. SPE/IADC Indian Drilling Technology Conference and Exhibition, 16-18 October 2006, Mumbai, India (SPE 104465)

Fredericks P, Reitsma D, Runggai T, et al. Successful implementation of first closed loop, multiservice control system for automated pressure management in a shallow gas well offshore Myanmar. IADC/SPE Drilling Conference, 4-6 March 2008, Orlando, Florida, USA (SPE 112651)

Godhavn J M. Control requirements for high-end automatic MPD operations. SPE/IADC Drilling Conference and Exhibition, 17-19 March 2009, Amsterdam, The Netherlands (SPE 119442)

Lyons J L. Valve Designer's Handbook. Translated by Yuan Y Q. Beijing: China Machine Press. 1991. 92-104 (in Chinese)

Miller A, Boyce G, Moheno L, et al. Innovative MPD techniques improve drilling success in Mexico. First International Oil Conference and Exhibition in Mexico, 31 August-2 September 2006, Cancun, Mexico (SPE 104030)

Santos H, Leuchtenberg C, Reid P, et al. Opening new exploration frontiers with the micro-flux control method for well design. Offshore Technology Conference, 3 May-6 May 2004, Houston, Texas (SPE 16622)

Santos H, Reid P, Jones J, et al. Developing the micro-flux control method Part 1: System development, field test preparation and results. SPE/IADC Middle East Drilling Technology Conference and Exhibition, 12-14 September 2005, Dubai, United Arab Emirates (SPE 97025)

Santos H, Catak E, Kinder J, et al. Kick detection and control in oilbased mud: Real well-test results using micro flux control equipment. SPE/IADC Drilling Conference, 20-22 February 2007a, Amsterdam, The Netherlands (SPE 105454)

Santos H, Catak E, Kinder J, et al. First field applications of micro flux control show very positive surprises. IADC/SPE Managed Pressure Drilling \& Underbalanced Operations, 28-29 March 2007b, Galveston, Texas, U.S.A. (SPE 108333)

Santos H, Muir K, Sonnemann P, et al. Optimizing and automating pressurized mud cap drilling with the micro-flux control method. SPE Asia Pacific Oil and Gas Conference and Exhibition, 20-22 October 2008, Perth, Australia (SPE 116492)

Yang J W and Zhang L R. Analysis of valve resistance. Valve. 2001. (2): 22-24 (in Chinese)

Yuan E X. Engineering Fluid Mechanics. Beijing: Petroleum Industry Press. 1986. 45-131 (in Chinese)

Zhang X H. Characteristics of the fixed throttle. Gas Industry. 2007. (5): 63-65 (in Chinese)

Zhou Y C, Yang X W and Fang S L. Development and field test of PCDS-I precise managed pressure drilling system. Petroleum Drilling Techniques. 2011. (4): 7-12 (in Chinese)

(Edited by Sun Yanhua) 